\title{
Real Time Cardan Shaft State Estimation of High-Speed Train Based on Ensemble Empirical Mode Decomposition
}

\author{
Cai Yi, ${ }^{1}$ Jianhui Lin,' ${ }^{1}$ Tengda Ruan, ${ }^{1}$ and Yanping $\mathrm{Li}^{2}$ \\ ${ }^{1}$ State Key Laboratory of Traction Power, Southwest Jiaotong University, Chengdu 610031, China \\ ${ }^{2}$ College of Mechanical Engineering, Southwest Jiaotong University, Chengdu 610031, China \\ Correspondence should be addressed to Cai Yi; justin.yi@163.com
}

Received 25 February 2015; Revised 21 May 2015; Accepted 31 May 2015

Academic Editor: Changjun Zheng

Copyright (c) 2015 Cai Yi et al. This is an open access article distributed under the Creative Commons Attribution License, which permits unrestricted use, distribution, and reproduction in any medium, provided the original work is properly cited.

\begin{abstract}
Due to the special location and structure of transmission system on high-speed train named CRH5, dynamic unbalance state of the cardan shaft will pose a threat to the train servicing safety, so effective methods that test the cardan shaft operating information and estimate the performance state in real time are needed. In this study a useful estimation method based on ensemble empirical mode decomposition (EEMD) is presented. By using this method, time-frequency characteristic of cardan shaft can be extracted effectively by separating the gearbox vibration acceleration data. Preliminary analysis suggests that the pinions rotating vibration separated from gearbox vibration by EEMD can be used as important assessment basis to estimate cardan shaft state. With two sets gearbox vibration signals collected from the in-service train at different running speed, the comparative analysis verifies that the proposed method has high effectiveness for cardan-shaft state estimate. Of course, it needs further research to quantify the performance state of cardan shaft based on this method.
\end{abstract}

\section{Introduction}

In order to achieve the dynamic performance of the train running at high speed, the transmission system structure of high-speed train is always used with body hanging or frame hanging method, both of which all need to use a coupling to adapt to the free movement of the wheel [1]. For the high-speed train centralized power, Blue Arrow EMU (Electric Multiple Units) used the six hollow shaft couplings, and French TGV adopted universal shaft couplings. For the high-speed distributed power, such as CRH1 (China Railway High-speed 1), CRH2 (China Railway High-speed 2), and CRH3 (China Railway High-speed 3), all used the drum gear coupling [2]. While the transmission system of CRH5 (China Railway High-speed 5) adopted the retractable cross cardan shaft and the traction motor suspended from the train body to reduce the bogie mass, both of the special structures help to improve vehicle dynamics performance but also improve the reliability and maintainability of the motor. So being different from other high-speed trains, the transmission system of CRH5 consists of the gearbox, cardan shaft, traction motor, other rotating parts, and supporting component parts, as shown in Figure 1. Motor is the drive device, which is installed at the bottom of the train equipment cabin to lighten the unsprung mass and promote the vehicle dynamic performance. Cardan shaft disposed longitudinally is connected to the motor and gearbox by cross gimbal at both ends, and its main function is to transfer the drive torque from motor to gearbox [3]. There is a set of conical gear pair in gearbox, and the pinion is connected with cardan shaft, so it has the synchronous rotating speed with the cardan shaft. The big gear is connected with axle bearing, which also have the same rotating speed. The transmission ratio of this transmission system is 2.22 .

The end of the cardan shaft is supported by rigid bearing and bearing seat; obviously, it is a typical rigid rotor mechanical system. Unbalance of the rotor system is the main inducement in rotating machinery fault [4]. The defect of design structure, the unreasonable and uneven of the materials, assembling error, and the strain of the long-term use all would lead to the unbalance of the rotor system. When the rotor system is in a working state of imbalance, 


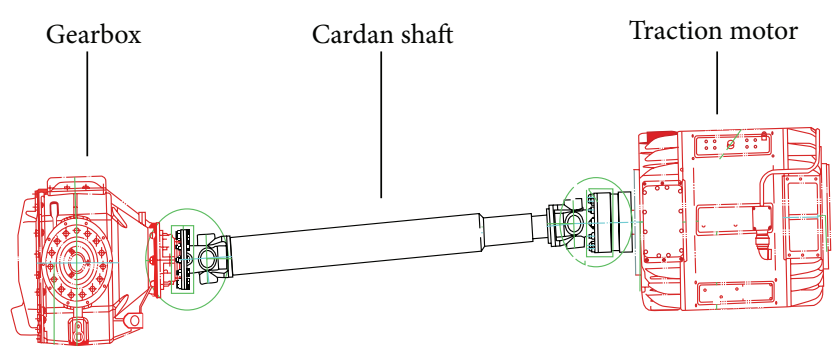

FIgURE 1: CRH5 transmission system.

its mass centre will offset from the rotation centre axis, which will lead to the bend of shaft, the internal pressure boosted, the abrasion of bearing parts accelerated, and even horrific accident [5]. So the unbalance state estimation in real time of cardan shaft is an important measure to ensure the operational safety for CRH5.

By considering practical engineering application, we focus on the indirect assessment method based on the gearbox vibration acceleration as there is no effective monitoring to directly access the signal of the cardan shaft state. The ends of cardan shaft are connected to the traction motor and gearbox, and maybe we could gain the state information of cardan shaft by one end or two, so we must explore and compare the vibration contribution of cardan shaft to two sides separately.

According to the structure of the traction motor, there is a spiral spring below the motor to achieve elastic suspension which buffer and weaken most of the vibrational energy of the motor $[6,7]$. The vibration contribution of dynamic imbalance of cardan shaft to the motor is relatively small, so it is negligible for the preliminary estimation of the cardan shaft state. However, it is quite necessary to monitor the vibration of the motor when we want to detect and identify the fault source of the transmission system accurately. On the other hand, the vibration contribution of dynamic imbalance of cardan shaft to the gearbox is quite significant, and the gearbox vibration contains more state information of the transmission system. To prove the effect relationship between gearbox vibration and cardan shaft state, we implemented the bench test which is shown in Figure 2.

There are three cardan shafts for the bench test, and the state of these shafts, respectively, is new (represented by the red line), special repairing (represented by the purple line), and close to the use limit (represented by the black line); the bench test result is shown in Figure 2. It can be seen clearly that the higher the speed is, the severer the dynamic imbalance state of the cardan shaft becomes and the larger the vibration of gearbox generated by cardan shaft is. Obviously, the gearbox vibration character to some extent reflects the dynamic imbalance state of cardan shaft.

For exploring the mapping relationship between the gearbox vibration and the cardan shaft state in practical application, we conducted an in-service train monitoring experiment and picked up the real-time detecting data while the train was running at the different speed. To avoid changing the structure of the transmission system and bringing additional risks to the train, the sensor was seated on the auxiliary hole where it is in upper of the gearbox to monitor the vibration acceleration of the gearbox, and as shown in Figure 3 it can be seen that an advantage of gearbox acceleration measurement device is their simple structures, which make it easier to carry out maintenance. However, the gearbox acceleration waveform contains too much vibration information, and the amplitude is affected greatly by the train running speed.

In this paper, we presented a method to measure cardan shaft on servicing high-speed train named CRH5 using gearbox vibration acceleration signal. Frequency family separation mechanism based on ensemble empirical mode decomposition (EEMD) is applied, and the target frequency band determination based on average instantaneous frequency and the dominant frequency of Fourier spectrum is proposed, which can be used as assessment basis for state estimation of cardan shaft. The novelty of this work is that the data analysis is based on real-world, and the signal processing technique should be suitable for on-line application, which have more practical significance.

The rest of this paper is organized as follows. In Section 2, the EMD algorithm is described, briefly; then EEMD and its superiority of decomposition are explained. Section 3 presents the method for state estimation. The verification of the proposed method with in-service train monitoring experiment is shown and discussed in Section 4. Section 5 summarizes the conclusion.

\section{Ensemble Empirical Mode Decomposition}

The review and principles of the EMD method are conducted based on $[8,9]$. Thanks to the definition of the interpolating splines, the extraction of a mean function $m(t)$ is possible and it can be removed from the initial signal $x(t)$ in order to obtain

$$
x_{1}(t)=x(t)-m(t) .
$$

The obtained signal $x_{1}(t)$ is now examined with the aim of evaluating if it respects the intrinsic mode functions (IMFs) definition. Each mode should be independent of the others. In this way, it can smooth uneven signals, and each signal could be decomposed into a number of IMFs [10-12]. An IMF represents a simple oscillatory mode compared with the simple harmonic function. If the two previous conditions are not satisfied, the resulting signal $x_{1}(t)$ is not an IMF, and then the previous stems are repeated. The sifting process runs until the extracted signal respects the two IMF conditions; then the function obtained represents the first intrinsic mode function $c_{1}(t)$ and it is subtracted from the initial signal:

$$
r_{1}(t)=x(t)-c_{1}(t),
$$

where $r_{1}(t)$ is the residual signal. This signal represents the input for the second IMF calculation by means of the sifting process. From the above and with the definition, any signal $x(t)$ can be decomposed as

$$
x(t)=\sum_{i=1}^{n} c_{i}+r_{n}(t) .
$$




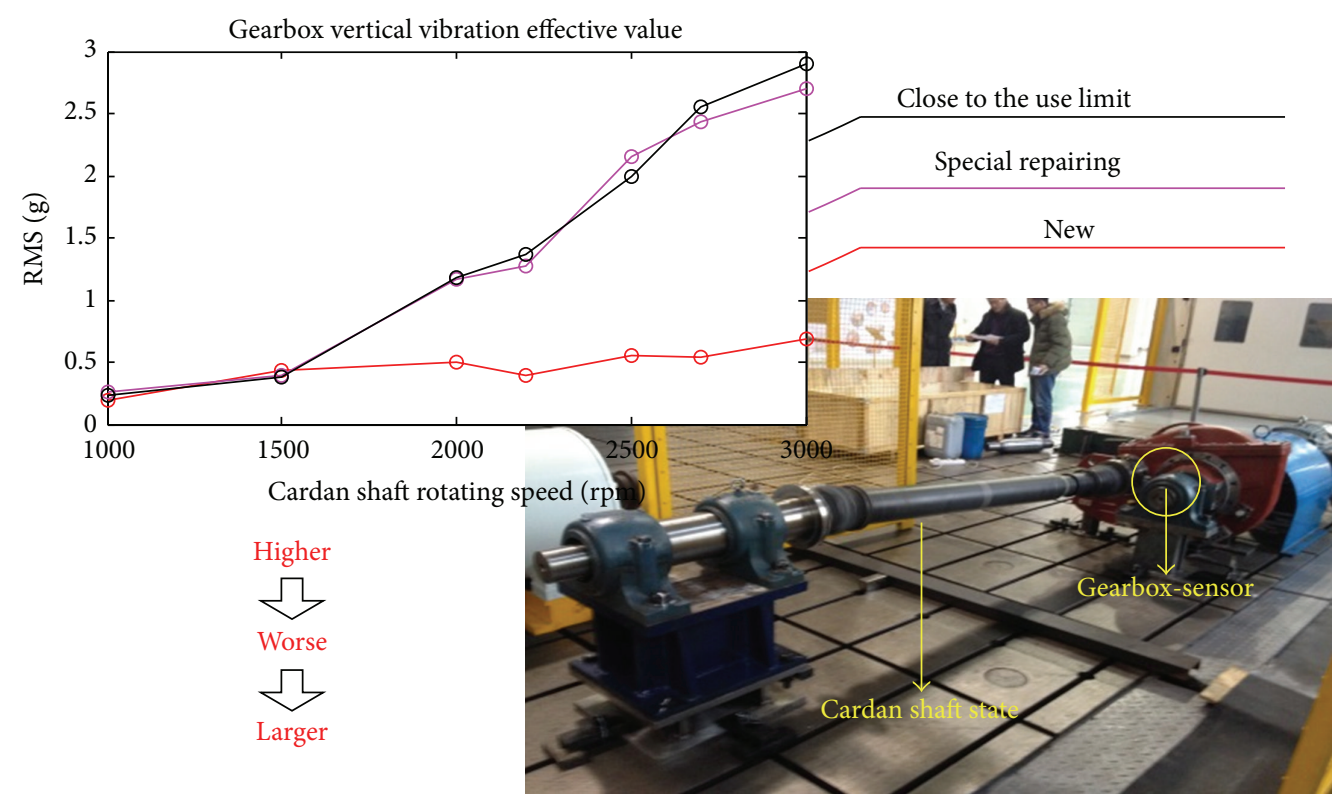

Figure 2: Cardan shaft beach test and test result.

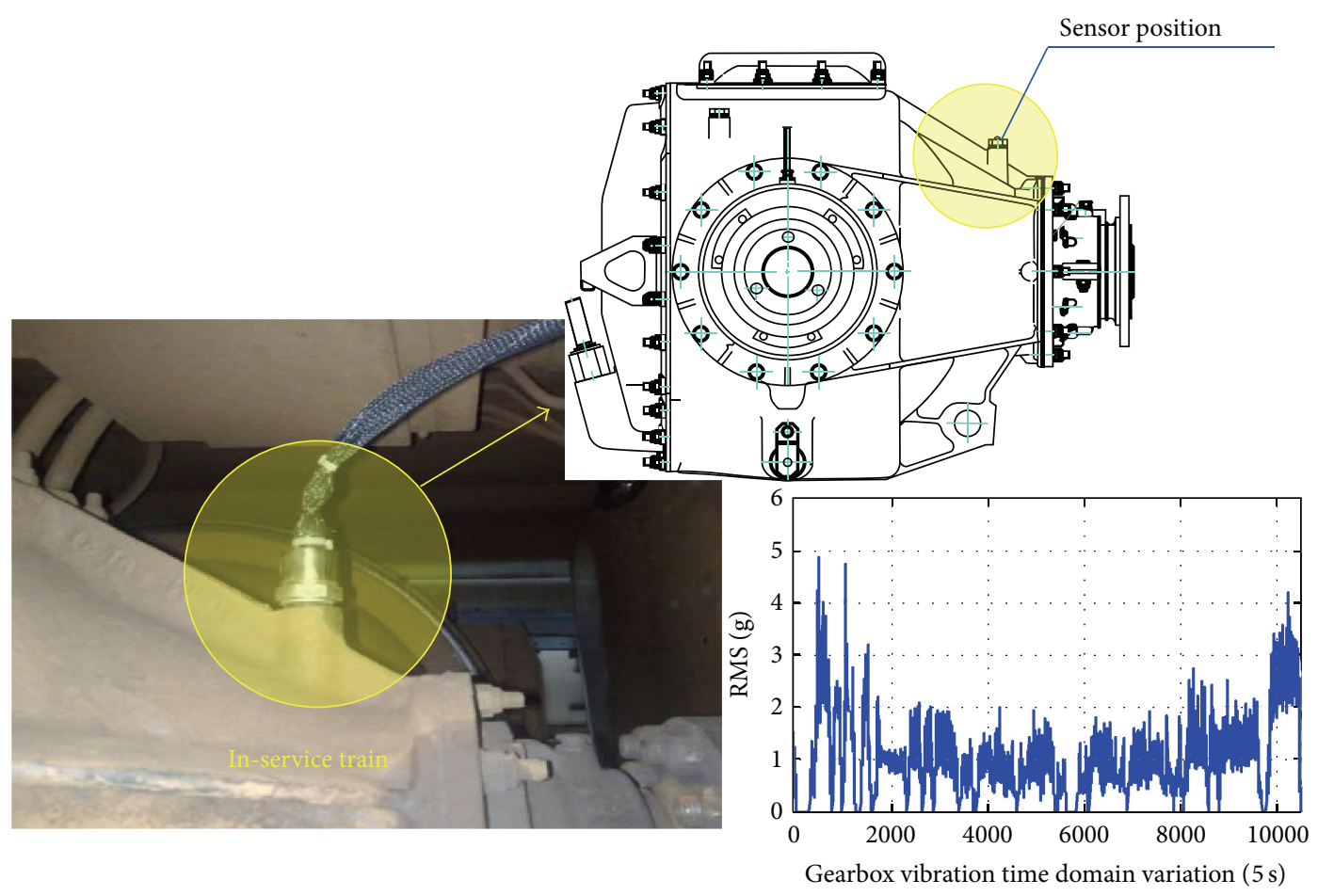

FIGURE 3: In-service train monitoring experiment.

The original signal can be expressed as the sum of all the IMFs and the residue. The IMFs include different frequency bands ranging from high to low.

Empirical mode decomposition is an adaptive timefrequency signal processing method and has been successfully applied to rotating machinery fault diagnosis and structure health monitoring such as structural damage detection [13], misalignment diagnosis [14], rolling bearing defect diagnosis $[15,16]$, and rotor fault diagnosis $[17,18]$. However, it cannot extract fault features accurately because of the problem of mode mixing [19]. To alleviate mode mixing, $\mathrm{Wu}$ and Huang develop ensemble empirical mode decomposition (EEMD) to improve EMD [20]. By adding noise to the original signal and calculating the means of IMFs repeatedly, compared with EMD, EEMD is more accurate and effective for rotating machinery fault diagnosis [21-23]. 
EEMD's Procedures Are as Follows

(1) Add a random white noise signal $n_{j}(t)$ to $x(t)$ :

$$
x_{j}(t)=x(t)+n_{j}(t),
$$

where $x_{j}(t)$ is the noise-added signal, $j=1,2,3, \ldots$, $M$, and $M$ is the number of trial.

(2) Decompose $x_{j}(t)$ into a series of intrinsic mode functions $c_{i, j}$ utilizing EMD as follows:

$$
x_{j}(t)=\sum_{i=1}^{N_{j}} c_{i j}+r_{N_{J}},
$$

where $c_{i j}$ denotes the $i$ th IMF of the $j$ th trial, $r_{N_{I}}$ denotes the residue of $j$ th trial, and $N_{j}$ is the IMFs number of the $j$ th trial.

(3) If $j<M$, then repeat steps (1) and (2) and add different random white noise signals each time.

(4) Obtain $I=\min \left(N_{1}, N_{2}, \ldots, N_{M}\right)$ and calculate the ensemble means of corresponding IMFs of the decompositions as the final result

$$
c_{i}=\frac{\left(\sum_{j=1}^{M} c_{i j}\right)}{M},
$$

where $i=1,2,3, \ldots, I$ and $c_{i}(i=1,2,3, \ldots, I)$ is the ensemble mean of corresponding IMF of the decompositions.

For each IMF $c_{i}(t)$, we can always have its Hilbert transform, and $f(t)$ can be expressed by convolution of $f(t)$ and $1 / \pi x$ as

$$
\begin{aligned}
\widehat{c}_{i}(t) & =c_{i}(t) * \frac{1}{\pi t}=\int_{-\infty}^{+\infty} c_{i}\left(t^{\prime}\right) \frac{1}{\pi\left(t-t^{\prime}\right)} d t \\
& =\int_{-\infty}^{+\infty} c_{i}\left(t-t^{\prime}\right) \frac{1}{\pi t^{\prime}} d t .
\end{aligned}
$$
by

Then the analytical signal of the original signal is obtained

$$
\begin{aligned}
& z_{i}(t)=c_{i}(t)+i \widehat{c}_{i}(t)=a_{i}(t) e^{j \theta_{i}(t)} . \\
& a_{i}(t)=\sqrt{c_{i}(t)^{2}+\widehat{c}_{i}(t)^{2}} . \\
& \theta_{i}(t)=\arctan \left(\frac{\widehat{c_{i}}(t)}{c_{i}(t)}\right) .
\end{aligned}
$$

Instantaneous amplitude and instantaneous phase are expressed by (9) and (10). In (10), we can have the instantaneous frequency as

$$
\omega_{i}(t)=\frac{d \theta_{i}(t)}{d(t)} .
$$

Then

$z_{i}(t)=c_{i}(t)+i \widehat{c}_{i}(t)=a_{i}(t) e^{j \theta_{i}(t)}=a_{i}(t) e^{j \int_{0}^{T} \omega_{i}(t) d t}$.
After performing the Hilbert transform to each IMF component, the original signal can be expressed as the real part $(\mathrm{Re})$ in the following form:

$$
\begin{aligned}
x(t) & =\sum_{i=1}^{n} c_{i}(t)=\operatorname{Re} \sum_{i=1}^{n} z_{i}(t)=\operatorname{Re} \sum_{i=1}^{n} a_{i}(t) e^{j \theta_{i}(t)} \\
& =\operatorname{Re} \sum_{i=1}^{n} a_{i}(t) e^{j \int_{0}^{T} \theta_{i}(t) d t} .
\end{aligned}
$$

Meanwhile, for the same signal $x(t)$, the Fourier expansion can be expressed as

$$
x(t)=\sum_{i=1}^{\infty} a_{i} e^{j \theta_{i} t} .
$$

From (13) and (14), it is shown that the Fourier transform is a special form of the HT. Amplitude variation and instantaneous frequency not only improve the effectiveness of decomposition significantly but also make HT based on EEMD suitable for nonstationary signals. The transformations of amplitude and frequency can be clearly separated by using each IMF component's expansion, which mitigates Fourier transform's limitation in terms of invariable amplitude and frequency. The time-frequency amplitude distribution is designated as the signal's Hilbert spectrum $H(\omega, t)$, which can accurately describe amplitude changes with time and frequency and further reflect the signal's inherent timevarying characteristics. With the Hilbert spectrum defined, the Hilbert marginal spectrum can be shown as

$$
\begin{aligned}
h(\omega) & =\int_{-\infty}^{+\infty} H(\omega, t) d t \\
& =\int_{-\infty}^{+\infty} \operatorname{Re} \sum_{i=0}^{n} a_{i}(t) e^{j \int_{0}^{T} \omega_{i}(t) d t} d t .
\end{aligned}
$$

Obviously, the Hilbert spectrum offers a measure of amplitude distribution from each frequency and time, while the marginal spectrum gives a measure of the total amplitude distribution from each frequency.

\section{The Method for State Estimation}

According to the motion transmission principles and structure of the transmission system, there are some characteristic frequencies which have high relativity with cardan shaft working condition being shaft rotation frequency, pinions rotating frequency, big gear rotating frequency, and gear mesh frequency. All of these characteristic frequencies are calculated with the real-time train speed $v$, wheel diameter $d$, and transmission ratio $i$. According to the structure of the cardan shaft and gearbox, the cardan shaft rotation frequency is approximately equal as pinions rotating frequency, and the big gear rotating frequency approximately equal as trainwheel rotation frequency. When the train is running at the speed $248 \mathrm{~km} / \mathrm{h}$, all the related parameters and characteristic frequencies are shown as Table 1. 
TABLE 1: Related parameter and characteristic frequencies.

\begin{tabular}{lc}
\hline Index & Value \\
\hline Train speed $(v)$ & $248 \mathrm{~km} / \mathrm{h}$ \\
Transmission ratio $(i)$ & 2.22 \\
Wheel diameter $(d)$ & $0.88 \mathrm{~m}$ \\
Number of teeth $(n)$ & 27 \\
Pinions rotating frequency $\left(f_{w}\right)$ & $55.35 \mathrm{~Hz}$ \\
Gear mesh frequency $\left(f_{n}\right)$ & $1494.35 \mathrm{~Hz}$ \\
Big gear rotating frequency $\left(f_{c}\right)$ & $24.93 \mathrm{~Hz}$ \\
\hline
\end{tabular}

Due to the sensor position locating on the upper of gearbox, where is not effected by the damping device of the bogie, the signal collected from gearbox contains a number of wheel-rail coupling vibration noise. In addition, the vibration of the wheel-shaft dynamic imbalance, cardan shaft dynamic imbalance, and the gear meshing would also be collected by the measuring point. When the cardan shaft with the dynamic imbalance or the gears with fatigue crack are meshing, both the amplitude and phase of vibration signal would be modulated. Leaving out the effect of transport function, the gearbox vibration signal picked up by sensor can be expressed as follows [24]:

$$
\begin{aligned}
y_{i} & (t) \\
& =\sum_{m=1}^{M} X_{m}\left[1+d_{m}\right] \cos \left[2 \pi m z f_{w}+\phi_{m}+b_{m}(t)\right],
\end{aligned}
$$

where $X_{m}$ is the amplitude of the $m$ component, $\phi_{m}$ is the phase, and $f_{w}$ is the main frequency. It is clear that it is an amplitude modulation and frequency modulation signal. Equation (14) can be also expressed as

$$
y(t)=\sum_{m=1}^{M} p_{m}(t) \cos \theta_{m}(t) .
$$

In addition, according to (7)-(10), each IMF which resulted from EEMD of the gearbox vibration signal can be expressed as

$$
c_{i}(t)=a_{i}(t) \cos \phi_{i}(t)
$$

As the envelope amplitude function $a_{i}(t)$ obtained by (9) is a slowly changing signal compared with the phase function $\phi_{i}(t)$ obtained by (10), each IMF $c_{i}(t)$ which resulted from EEMD can be the signal which contains the frequency and phase information. Therefore, omitting the residual $r_{n},(3) \mathrm{can}$ be expressed as

$$
x(t)=\sum_{i=1}^{n} a_{i}(t) \cos \phi_{i}(t) .
$$

By comparing (17) and (19), we know that gearbox vibration signal consists of a number of frequency family components, each of which is an amplitude modulation signal. On the other hand, the gearbox vibration signal consists of a number of IMFs, each of which is also exactly
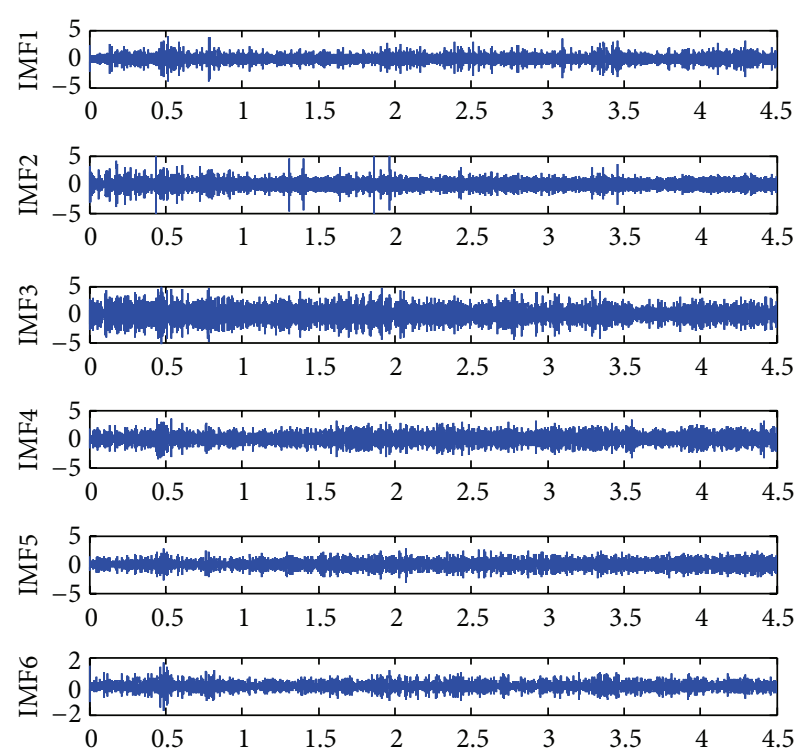

FIGURE 4: The IMF1 6 of one set gearbox vibration acceleration at speed $248 \mathrm{~km} / \mathrm{h}$.

a modulation signal. The representation forms in (17) and (19) are different. However, the representative frequency components are consistent. Therefore, it is viable to apply EEMD method to decompose the gearbox vibration signal into a number of IMF components, in which it contains the information of the cardan shaft dynamic unbalance state and other faults in the transmission system.

Freely choose one set of gearbox vibration acceleration signal to analysis by EEMD, which is collected from inservice train with a new cardan shaft at $248 \mathrm{~km} / \mathrm{h}$ running speed. In this case, the noise added has amplitude (standard deviation) of 0.30, and the ensemble number of EEMD is 100. The total number of IMFs is specified as $\log 2(N)-1$, in some occasions, the components may be excessively extracted, and in these cases the sum of the latest columns may already satisfy the definition of a trend; in this paper, the number of the IMFs is fixed as 20 by experience. Figures 4 and 5 give the IMFs of this set data and the residue. It appears that the first IMFs describe high frequency phenomena while the last one is related to the low frequency components of the signals that could have no physical meaning and could be due to the stop criteria set in the sifting process. So the IMF1-IMF19 are the effective frequency components, and the IMF20 is the residual frequency component that the whole signal deducts IMF1-19, represented by a trend.

Then how to make sure the target family frequency or corresponding IMFs component which is representative the characteristic frequency, for example, gear mesh frequency? There are two calculation methods to survey the frequency characteristic of every IMF: one is the average instantaneous frequency called A.I.F by us and the other is the dominant frequency of Fourier spectrum called D.F.F by us; the calculation results are shown as Figure 6. Due to the complexity and uncertainty of actual monitoring data in real-world, two 
TABLE 2: The frequency characteristic of the IMFs shown in Figures 10 and 11.

\begin{tabular}{lcccccccccccc}
\hline IMF & 1 & 2 & $\mathbf{3}$ & 4 & 5 & 6 & 7 & $\mathbf{8}$ & 9 & $\mathbf{1 0}$ & 11 & 12 \\
\hline A.I.F/Hz & 4845 & 3222 & $\mathbf{1 5 4 9}$ & 877 & 559.9 & 396.3 & 209.3 & $\mathbf{5 7 . 1}$ & 42.3 & $\mathbf{2 6 . 8}$ & 15.3 & 7.2 \\
D.F.F/Hz & 4662 & 2998 & $\mathbf{1 4 9 9}$ & 860.7 & 599.6 & 424.7 & 166.4 & $\mathbf{5 3 . 3}$ & 39.6 & $\mathbf{2 7 . 3}$ & 14.9 & 6 \\
\hline
\end{tabular}
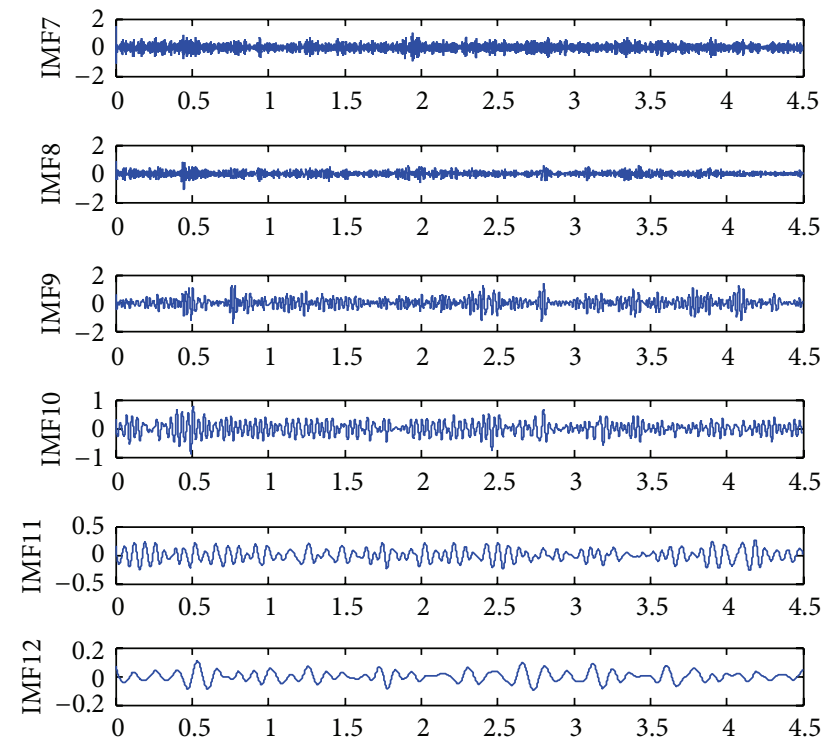

FIGURE 5: The IMF7 12 of one set gearbox vibration acceleration at speed $248 \mathrm{~km} / \mathrm{h}$.

calculation methods all are used to ensure the credibility and reliability of the vibration signals and method.

From Figure 6 we see that the average instantaneous frequencies of the IMFs are basically consistent with the dominant frequencies of Fourier spectrum of every IMF except IMF1. Moreover, when the train running speed is $248 \mathrm{~km} / \mathrm{h}$, the meshing frequency of the transmission system is $1494.35 \mathrm{~Hz}$, the pinions rotating frequency is $55.35 \mathrm{~Hz}$, and the big gear rotating frequency is $24.93 \mathrm{~Hz}$; therefore IMF3 is identified as the corresponding intrinsic mode function of the gear mesh vibration, IMF8 as the corresponding one of the pinions rotating vibration, and IMF10 as the corresponding one of the big gear rotating vibration. The details of the timefrequencies characteristic of the original signal, IMF3, IMF8, and IMF10, are shown as Figures 7 and 8, which verifies that although there always is great amount noise in the collected data of the gearbox vibration in high-speed train from realworld, it is very efficient to separate the vibration frequency family of the signal by using EEMD; there is a high fit degree between the original signal and gear mesh vibration, and pinions rotating vibration curve is the centre line of their changing curve; the big gear rotating vibration value is almost constant when the train running speed remains stable, which changes over the speed of the train. So for the contribution amount of the measuring point vibration, the gear mesh vibration and the pinions rotating vibration are bigger than the big gear rotating vibration; on the other hand, based on this measuring point seated on the auxiliary hole in upper of the gearbox, the gear mesh vibration and the pinions rotating vibration are more likely to be used to assess the work state of cardan shaft.

IMF3 and IMF8 are exerted to Hilbert transform to get the Hilbert instantaneous frequency spectrum, and the spectrum features can be surveyed from Figure 9. By comparing the frequency characteristic of the gear meshing vibration and the pinions rotation, the energy of the pinions rotating vibration is more stable and constant when the high-speed train keeps a certain speed, and the stability of the characteristic value is the key property for evaluating benchmark; according to the structure of the transmission system, the cardan shaft rotation frequency is approximately equal as pinions rotating frequency, so the vibration contribution of cardan shaft rotation to the measuring point is passed through the pinions rotation. From what has been discussed above, we fully believe that the frequency characteristic of the pinions rotating vibration separated by EEMD can be used as important assessment basis to estimate the work state of cardan shaft in operating high-speed train.

\section{Verification with In-Service Train Monitoring Experiment}

There is another set of gearbox vibration signals collected from the same in-service high-speed train at the same pathway, and of course, they are also at the same speed $248 \mathrm{~km} / \mathrm{h}$; however, in this transmission system the cardan shaft is close to the use limit, whose unbalance value is $355.2 \mathrm{gcm}$ (the unbalance value of the criterion old cardan shaft is $384 \mathrm{gcm}$ ), and the new cardan shaft was used to take the place of this old one. Figures 10 and 11 describe the EEMD calculated result of the gearbox vibration whose cardan shaft is close to the use limit. To catch the target family frequency, we calculate the A.I.F and D.F.F of IMF1-12 shown in Table 2. Obviously, IMF3 is identified as the corresponding intrinsic mode function of the gear mesh vibration, IMF8 as the pinions rotating vibration, and IMF10 as the big gear rotating vibration, which are coincident with the new cardan shaft.

Comparing the IMF3, IMF8, and IMF10 of gearbox vibration whose cardan shaft is close to the use limit with the new cardan shaft, respectively, is to demonstrate the effectiveness of the conclusion in Section 3, and the results are shown in Figures 12-14. The gear mesh vibrations of the old cardan shaft and new one are basically identical described by Figure 11, and there is no regularity for the big gear rotating vibrations shown in Figure 13; it follows that when the work state of cardan shaft is worse, there is almost no obvious change for gear mesh vibration and big gear rotating vibration. However, to the cardan shaft close to use limit and the new one, the pinions rotating vibration shows apparently 


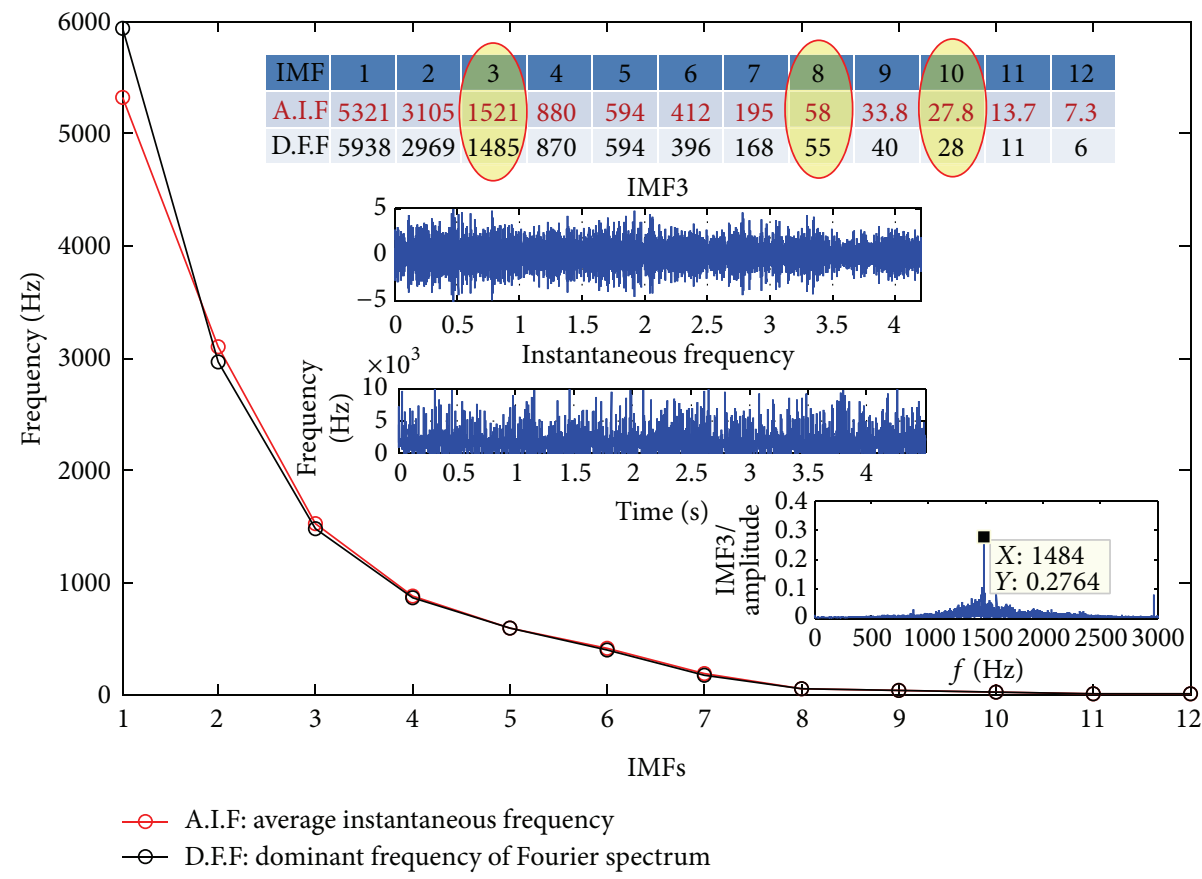

FIgURE 6: The frequency characteristic of the IMFs shown in Figures 4 and 5.

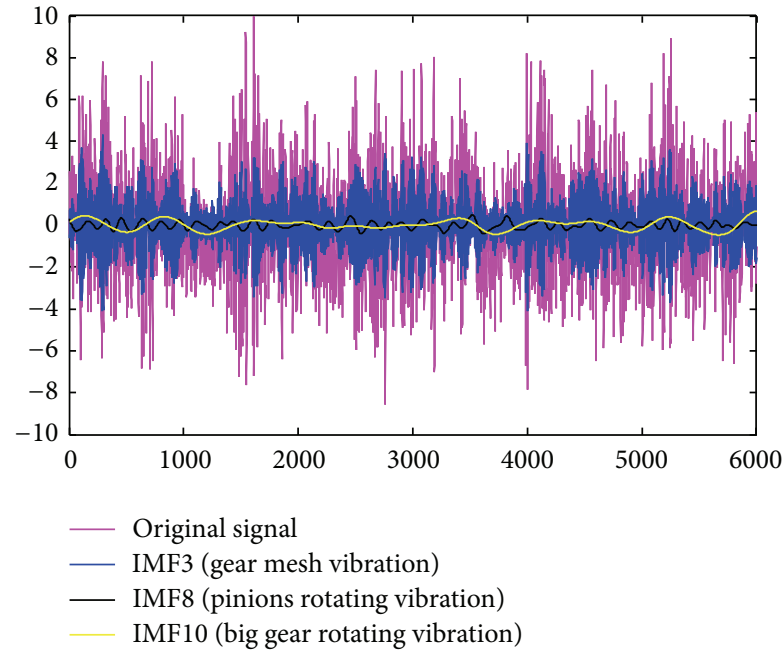

FIgURE 7: The time domain characteristic of the original signal, IMF3, IMF8, and IMF10.

sensitive characteristics; in a measure apparently, the pinions rotating vibration amplitude of the cardan shaft close to the use limit is much larger than the new one described in Figure 12.

All of above seems that the method and analysis conclusion are effective and correct described in Section 3 when the two kinds of work state of cardan shaft are servicing in the train running speed at $248 \mathrm{~km} / \mathrm{h}$; if the cardan shaft is in another different kind of operating mode, would we get the same conclusion? There are two sets gearbox vibration signals collected from the same in-service high-speed train

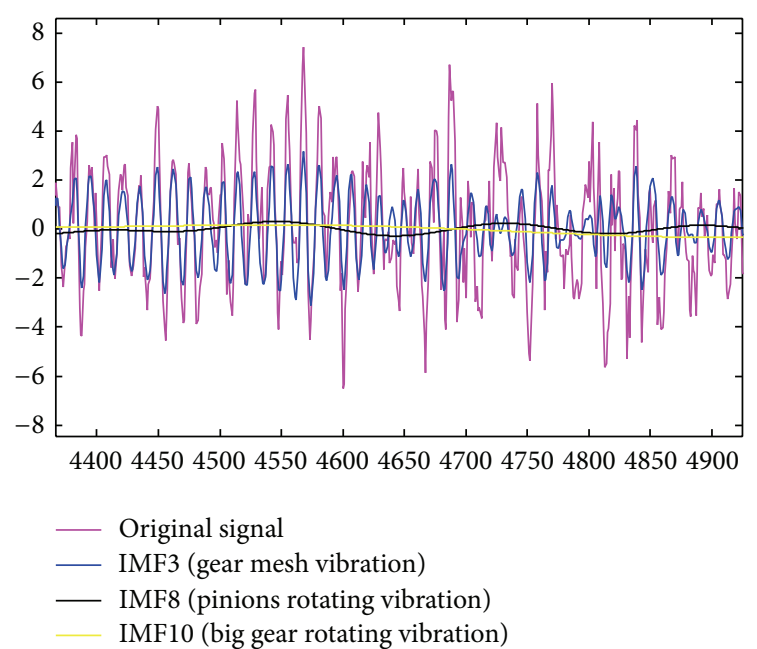

Figure 8: The detailed drawing of Figure 7.

and the same two state cardan shafts but at different pathway with the above signals; however, one set data is collected at the train running speed $199 \mathrm{~km} / \mathrm{h}$ when the old cardan shaft which is close to the use limit has not been replaced by the new one, and the other set is collected at the train running speed $201 \mathrm{~km} / \mathrm{h}$ which has the new cardan shaft. All the related parameters and characteristic frequencies of the two sets signals are shown as Table 3, and the IMFs are described by Figures 15-18.

In general, when the train is running at a lower speed, the vibration response amplitude of the measuring point is smaller; where $T_{1}=T_{2}$, the time period of periodic shock waves presented in IMF7, respectively, in Figures 16 and 18 


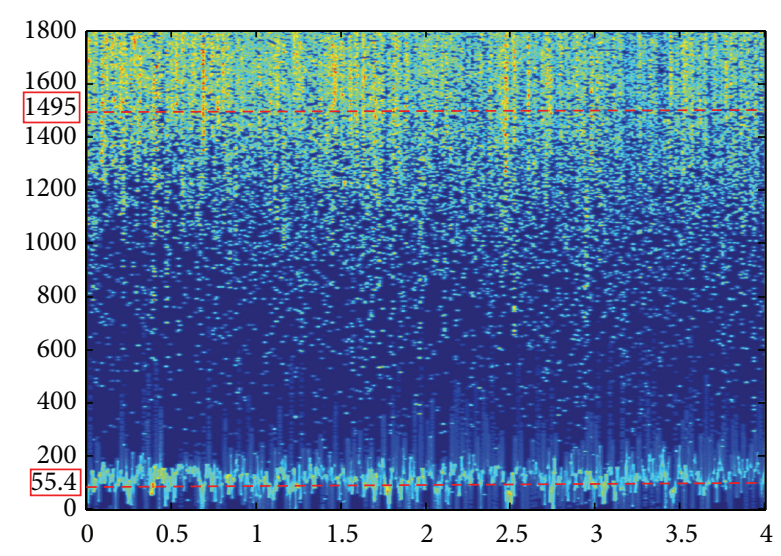

Figure 9: The instantaneous frequency spectrum of IMF3 and IMF8.
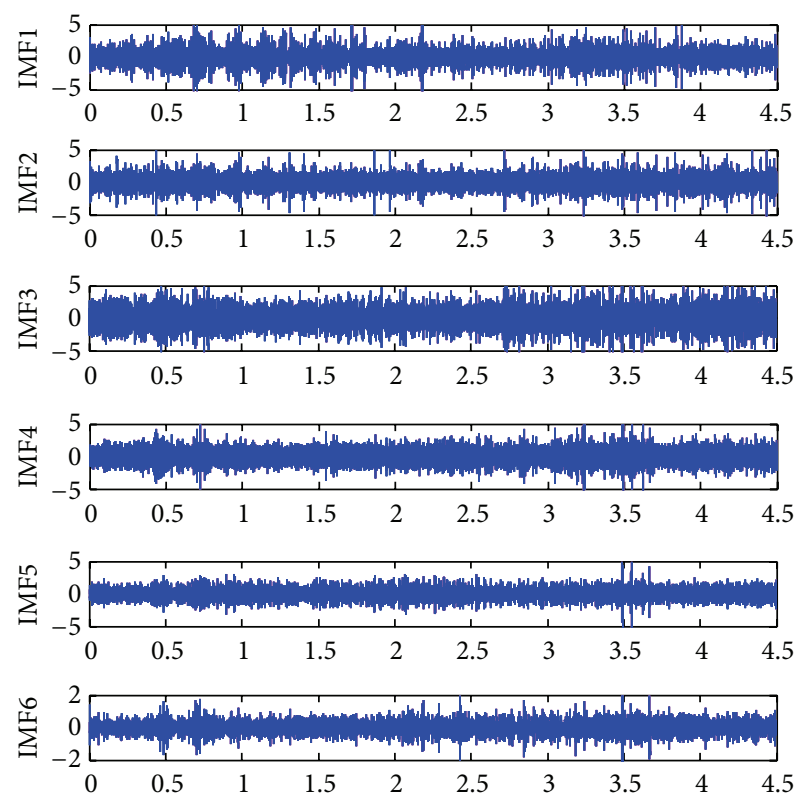

FIGURE 10: The IMF1 6 of gearbox vibration whose cardan shaft close to use limit at speed $248 \mathrm{~km} / \mathrm{h}$.

is consistent, which may be caused by the wheel-rail impact; however, its further verification needs to take into account the rail state and line information. Calculating the A.I.F and D.F.F of IMF 1-12 is shown in Table 4, and comparing with Table 3, obviously, IMF4 is identified as the corresponding intrinsic mode function of the gear mesh vibration and IMF9 as the pinions rotating vibration, which are different from the situation when the train running speed is $248 \mathrm{~km} / \mathrm{h}$.

Figure 19 is the comparison of gear mesh and pinions rotating vibration at two kinds of cardan shaft states: one is close to the use limit at train running speed $199 \mathrm{~km} / \mathrm{h}$ and the other is a new one at train running speed $201 \mathrm{~km} / \mathrm{h}$. This figure shows that the time domain amplitude of gear mesh vibration is almost overlapping although the state of one cardan shaft has been close to the use limit when they are servicing at the same speed; however, there is significant
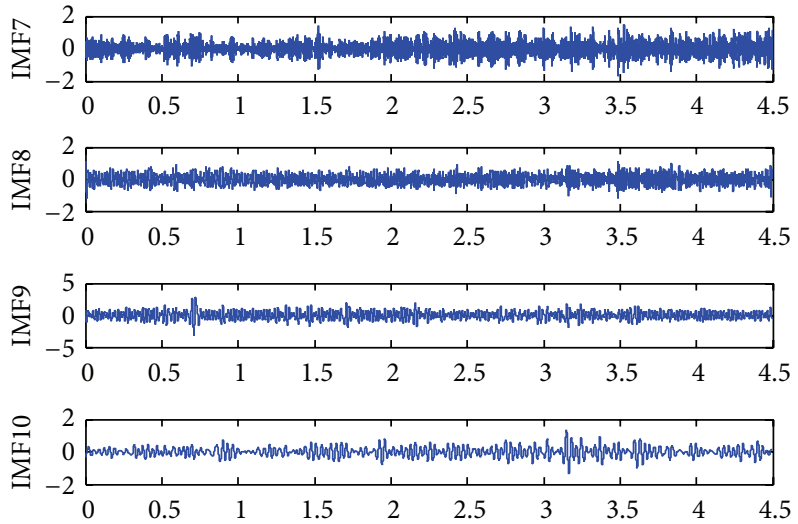

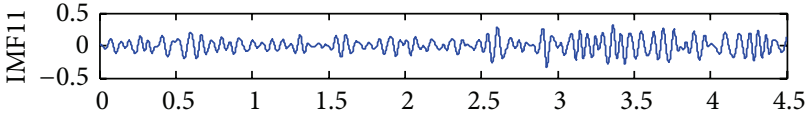

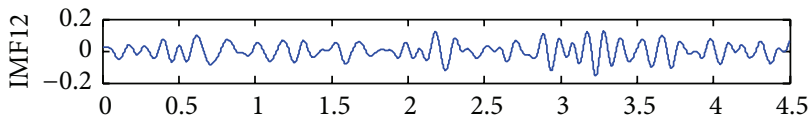

FIGURE 11: The IMF7 12 of gearbox vibration whose cardan shaft close to use limit at speed $248 \mathrm{~km} / \mathrm{h}$.

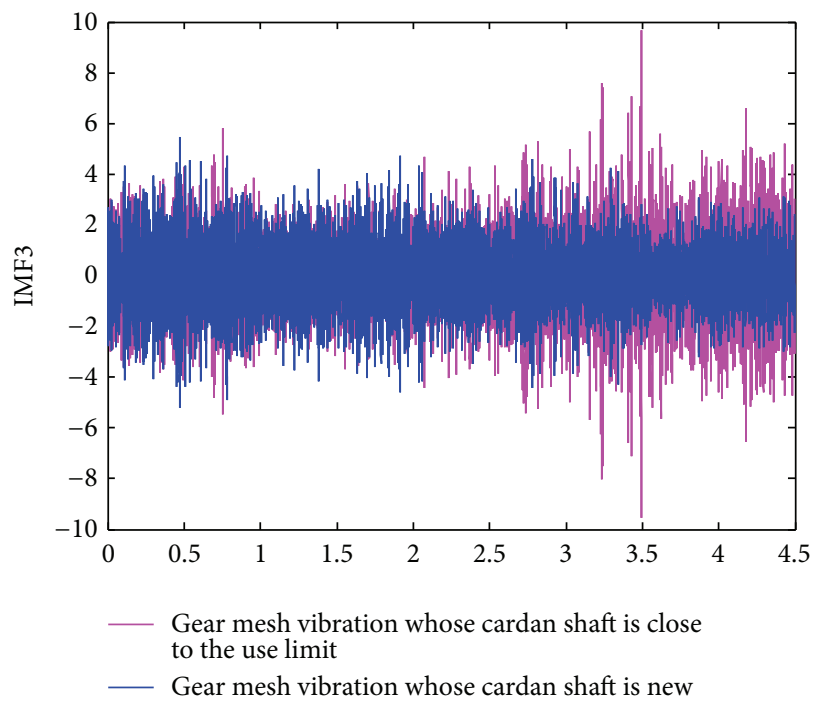

FIGURE 12: The compare of gear mesh vibration of two states of cardan shaft at speed $248 \mathrm{~km} / \mathrm{h}$.

TABLE 3: Related parameter and characteristic frequencies.

\begin{tabular}{lcc}
\hline Index & $\begin{array}{c}\text { Value (the old } \\
\text { shaft) }\end{array}$ & $\begin{array}{c}\text { Value (the new } \\
\text { shaft) }\end{array}$ \\
\hline $\begin{array}{l}\text { Train speed } v \\
\text { Pinions rotating } \\
\text { frequency } f_{w}\end{array}$ & $199 \mathrm{~km} / \mathrm{h}$ & $201 \mathrm{~km} / \mathrm{h}$ \\
$\begin{array}{l}\text { Gear mesh frequency } f_{n} \\
\begin{array}{l}\text { Big gear rotating } \\
\text { frequency } f_{c}\end{array}\end{array}$ & $44.4 \mathrm{~Hz}$ & $44.8 \mathrm{~Hz}$ \\
\hline
\end{tabular}

difference between the pinions rotating vibration of the new cardan shaft and the old one. As a result, the method and 


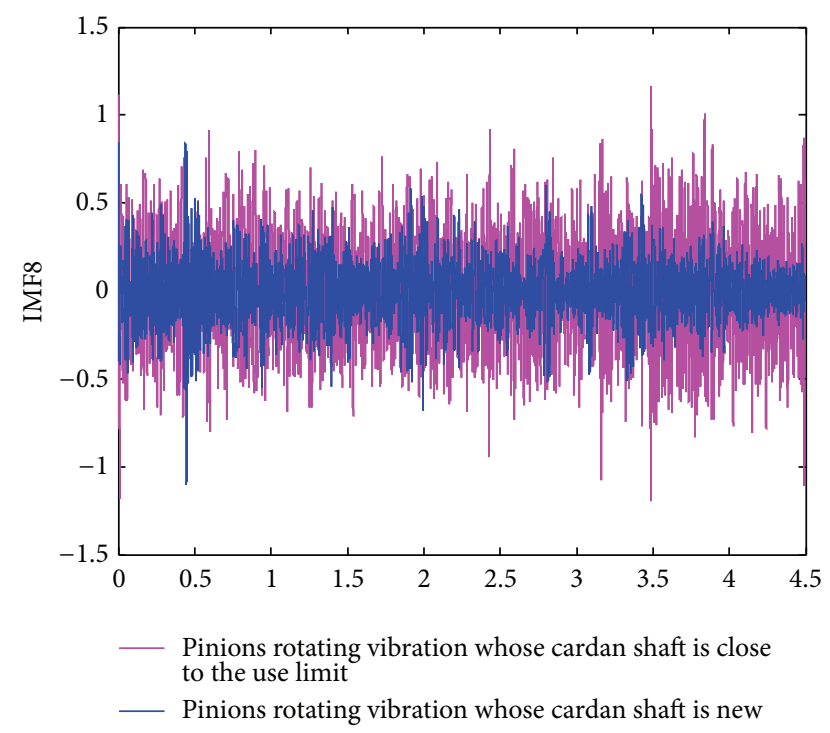

Figure 13: The compare of pinions rotating vibration of two states of cardan shaft at speed $248 \mathrm{~km} / \mathrm{h}$.

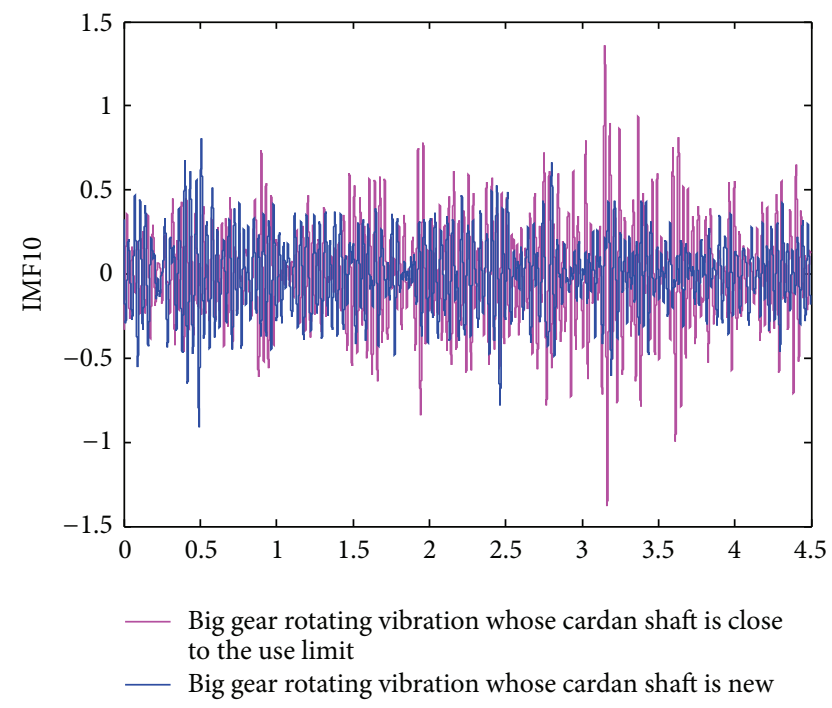

FIGURE 14: The compare of big gear rotating vibration of two states of cardan shaft at speed $248 \mathrm{~km} / \mathrm{h}$.

analysis conclusion are also effective and correct described in Section 3 when the train is running at another speed level.

Figure 20 is another comparison of gear mesh and pinions rotating vibration at two kinds of cardan shaft state: one which is close to the use limit is at train running speed $199 \mathrm{~km} / \mathrm{h}$, but the new one is at train running speed $250 \mathrm{~km} / \mathrm{h}$. Because the running speed of the new cardan shaft is higher, the time domain amplitude of the gear mesh vibration is also bigger than the old one, which has been verified in the previous section; however, although the speed rating of the new cardan shaft is higher than the old one, the pinions rotating vibration amplitude of the new one is smaller than the old one on the contrary. So this is more persuasive to verify that the pinions rotating vibration characteristics
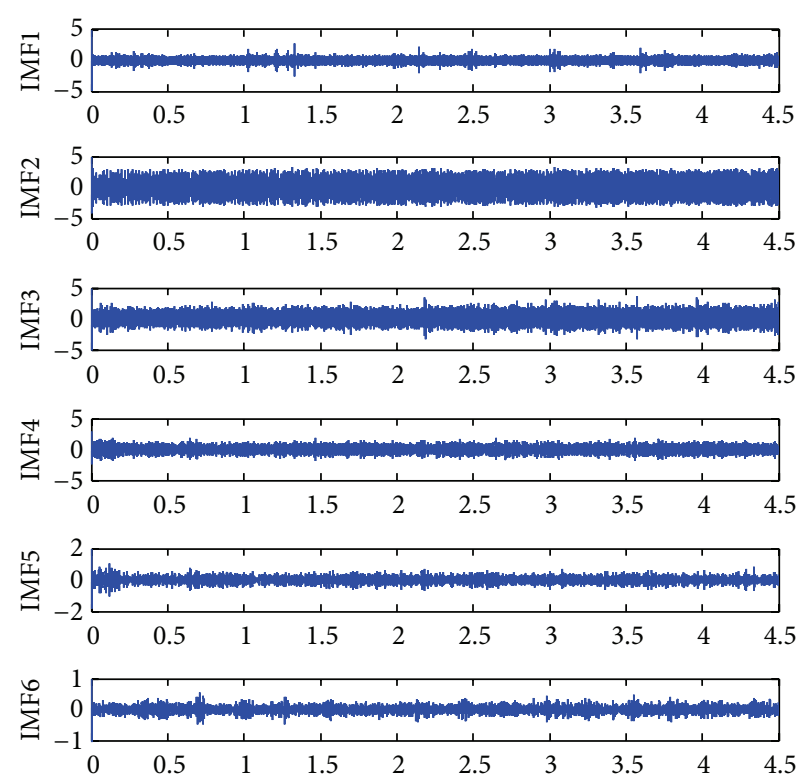

FIGURE 15: The IMF1 6 of gearbox vibration whose cardan shaft close to use limit at speed $199 \mathrm{~km} / \mathrm{h}$.
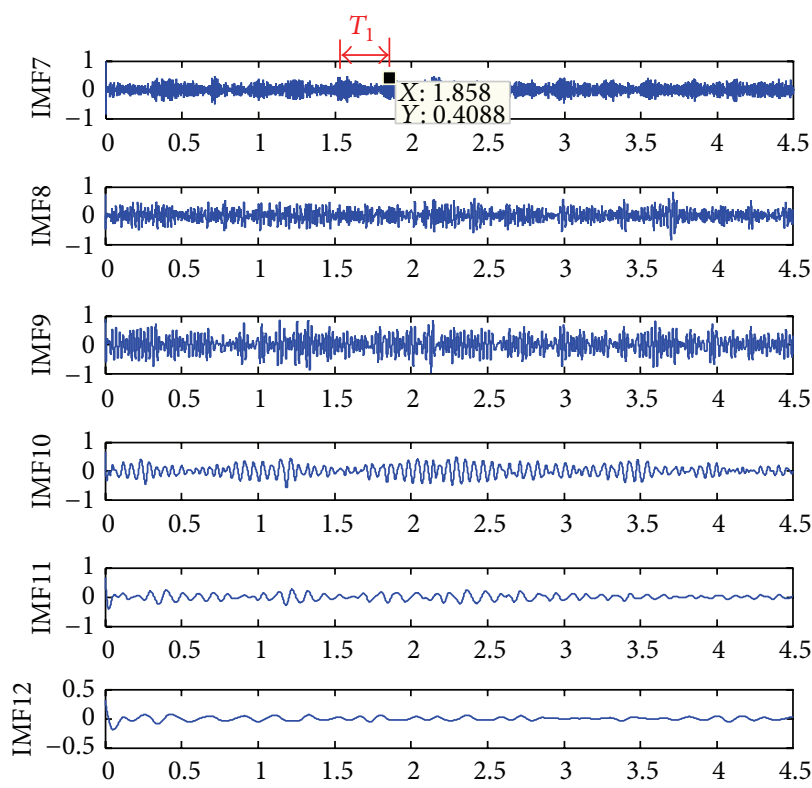

FIGURE 16: The IMF7 12 of gearbox vibration whose cardan shaft close to use limit at speed $199 \mathrm{~km} / \mathrm{h}$.

separated by EEMD can be used as important assessment basis to estimate the work state of cardan shaft in operating high-speed train.

\section{Conclusion}

In this paper, a state estimation method and technique based on EEMD are proposed to identify the work state of cardan shaft in case of in in-service high-speed train. The vibration signals of running transmission system with the cardan shaft 

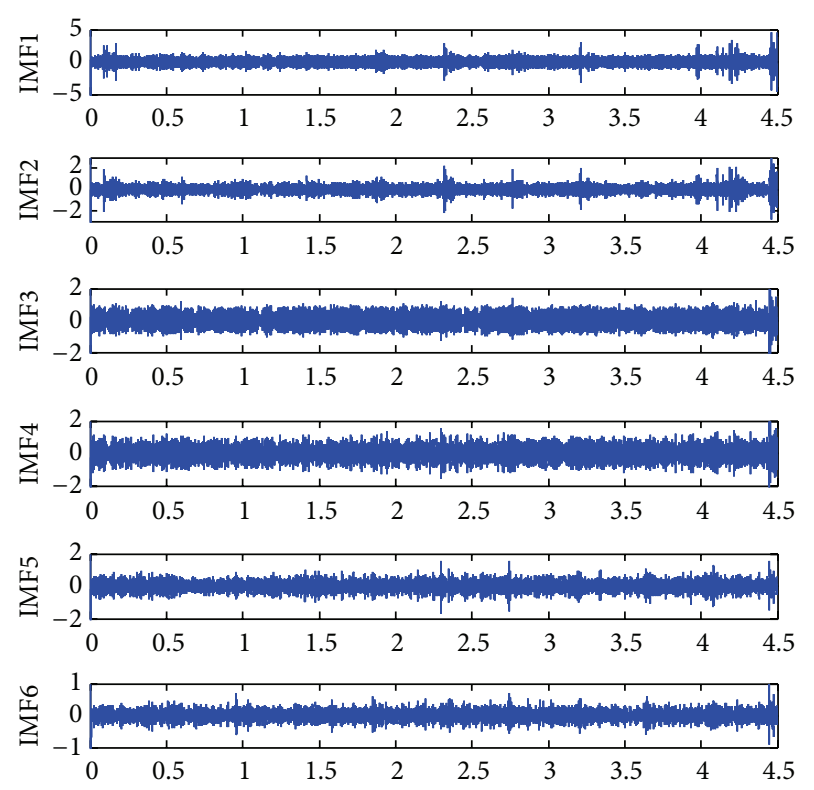

FIGURE 17: The IMF1 6 of gearbox vibration whose cardan shaft is new at speed $201 \mathrm{~km} / \mathrm{h}$.
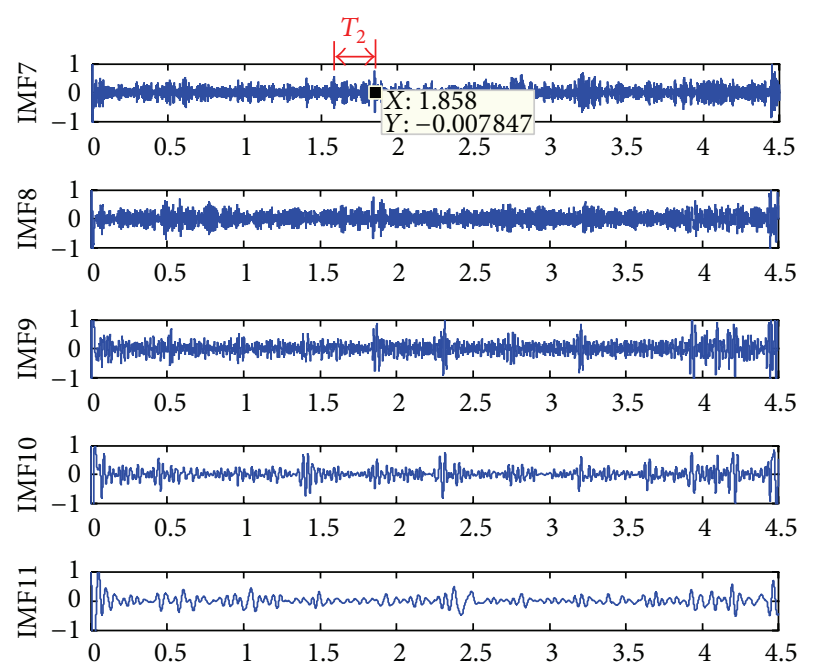

$$
\sum_{-1}^{*}{ }_{0}^{1}
$$

FIGURE 18: The IMF7 12 of gearbox vibration whose cardan shaft is new at speed $201 \mathrm{~km} / \mathrm{h}$.

at the bad work state, including unbalance and damage, are decomposed by EEMD method and the target family frequency of the associated IMF is determined by using A.I.F and D.F.F calculation method. The calculation result shows that the frequency characteristic of the pinions rotation can be used as important assessment basis to estimate the work state of cardan shaft in operating high-speed train, and the effectiveness and usefulness of the proposed method are verified by two sets gearbox vibration signals collected
TABLE 4: The frequency characteristic of the IMFs shown in Figures $15-18$.

\begin{tabular}{lcccc}
\hline \multirow{2}{*}{ IMF } & \multicolumn{2}{c}{ Old shaft } & \multicolumn{2}{c}{ New shaft } \\
& A.I.F/Hz & D.F.F/Hz & A.I.F/Hz & D.F.F/Hz \\
\hline 1 & 4694 & 5252.4 & 5235 & 5360.2 \\
2 & 2340 & 2377.9 & 3524 & 3111.3 \\
3 & 1664 & 1401.3 & 2416 & 2302.2 \\
4 & $\mathbf{1 1 7 0}$ & $\mathbf{1 1 9 7 . 1}$ & $\mathbf{1 2 0 8}$ & $\mathbf{1 2 3 2 . 9}$ \\
5 & 598.7 & 601.9 & 624.2 & 755.5 \\
6 & 222.2 & 296.9 & 523.6 & 523.5 \\
7 & 172.2 & 176 & 201.3 & 230.2 \\
8 & 89.6 & 68.2 & 93.11 & 105.5 \\
9 & $\mathbf{4 3 . 1}$ & $\mathbf{4 2 . 2}$ & $\mathbf{4 4 . 8 9}$ & $\mathbf{4 5 . 3}$ \\
10 & 19.2 & 18.8 & 33.56 & 36.8 \\
11 & 8.7 & 9.9 & 21.44 & 23.7 \\
12 & 4.2 & 5.5 & 9.11 & 9.3 \\
\hline
\end{tabular}
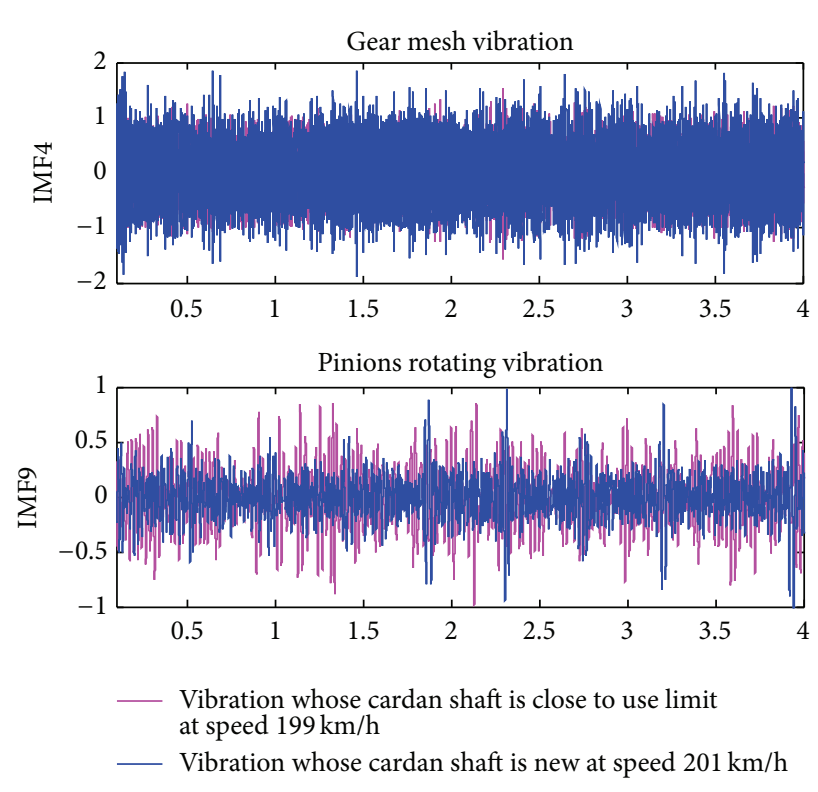

FIGURE 19: The compare of gear mesh vibration and pinions rotating vibration under two states of cardan shaft at speed $199 \mathrm{~km} / \mathrm{h}$ versus $201 \mathrm{~km} / \mathrm{h}$.

from the in-service train at different speed. According to the research work in this paper, it also can be concluded that

(1) EEMD can decompose the signal into a number of IMF; each IMF contains the sampling frequency and also changes with the signal itself. So EEMD method has shown great recognition performances in analyzing the nonlinear and nonstationary signals in practical application of real-world;

(2) considering that there is no effective monitoring to directly access the signal of the cardan shaft state, it is feasible to estimate the work state of cardan shaft from gearbox vibration by EEMD method, where the sensor is seated on the auxiliary hole in upper of the gearbox; 

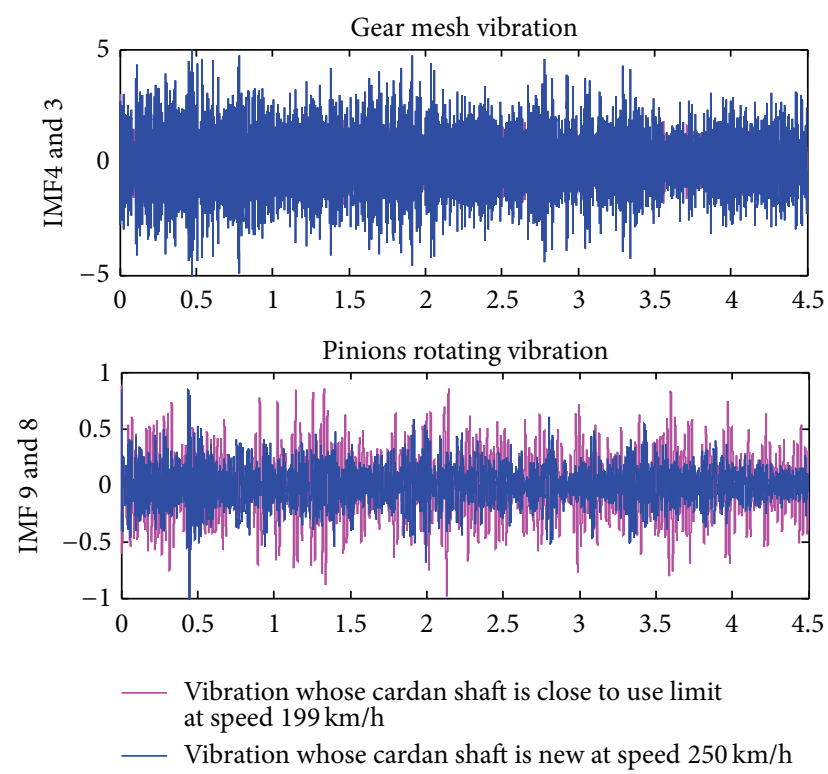

FIGURE 20: The compare of gear mesh vibration and pinions rotating vibration under two states of cardan shaft at speed $199 \mathrm{~km} / \mathrm{h}$ versus $250 \mathrm{~km} / \mathrm{h}$.

(3) of course, there still is too much further research work to do to format the quantitative estimation method for quantifying the work state of cardan shaft in inservice high-speed train on line.

\section{Conflict of Interests}

The authors declare that there is no conflict of interests regarding the publication of this paper.

\section{Acknowledgment}

The research work described in this paper is supported by Traction Power State Key Laboratory and Changzhou Southwest Jiaotong University Rail Transit Institute, China, under the Project nos. 2013J008-A, BY201003, and CE20110062.

\section{References}

[1] Y. Luo and D. C. Jin, "Research on the rules of suspension parameters to driving equipment suspended in bogie frames," China Railway Science, vol. 28, no. 4, pp. 36-42, 2007.

[2] W. S. Zhong, S. N. Xiao, and H. Y. Liu, "Development and experimental research of light frame used in high speed power bogie," Journal of the China Railway Society, vol. 20, no. 2, pp. 32-37, 1998.

[3] Y. M. Su and Z. Y. Wang, "Research on rotating machinery fault mechanism," Journal of Yangtze University (Natural Science Edition), vol. 4, no. 4, pp. 55-59, 2009.

[4] G. A. Yang, Rotor Balancing Practical Techniques, China Petrochemical Press, Beijing, China, 2012.

[5] S. Leva, A. P. Morando, and P. Colombaioni, "Dynamic analysis of a high-speed train," IEEE Transactions on Vehicular Technology, vol. 57, no. 1, pp. 107-119, 2008.
[6] Y. Liu, X. J. Zhang, Y. M. Zhang, and Y. G. Meng, "Experimental research on reasonable lubricant quantity for transmission gears used in high-speed train," Science China Technological Sciences, vol. 55, no. 12, pp. 3455-3461, 2012.

[7] H. J. Zhang, Y. Yao, Y. Luo, and Q.-Z. Li, "Analysis on technical characteristics of CRH5 cardan drive system," Journal of the China Railway Society, vol. 31, no. 2, pp. 115-119, 2009.

[8] N. E. Huang, Z. Shen, and S. R. Long, "The empirical mode decomposition and the Hilbert spectrum for nonlinear and non-stationary time series analysis," Proceedings of the Royal Society of London, Series A, vol. 454, pp. 903-995, 1998.

[9] R. Ricci, P. Pennacchi, M. Lombardi, and C. Mirabile, "Failure diagnostics of a spiral bevel gearbox using EMD and HHT," in Proceedings of the ISMA2010 Including USD, pp. 2965-2979, 2010.

[10] N. E. Huang and S. S. P. Shen, Hilbert-Huang Transform and Its Application, vol. 4, World Scientific, Singapore, 2005.

[11] N. E. Huang, Z. Shen, S. R. Long, and N. E. Huang, "The empirical mode decomposition and the Hilbert spectrum for nonlinear and non-stationary time series analysis," Proceedings of the Royal Society of London, Series A, vol. 454, pp. 903-995, 1998.

[12] N. E. Huang, Z. Shen, S. R. Long et al., "The empirical mode decomposition and the Hilbert spectrum for nonlinear and non-stationary time series analysis," Proceedings of the Royal Society of London Series A, vol. 454, no. 1971, pp. 903-995, 1998.

[13] H. Li, X. Deng, and H. Dai, "Structural damage detection using the combination method of EMD and wavelet analysis," Mechanical Systems and Signal Processing, vol. 21, no. 1, pp. 298306, 2007.

[14] T. Y. Wu and Y. L. Chung, "Misalignment diagnosis of rotating machinery through vibration analysis via the hybrid EEMD and EMD approach," Smart Materials and Structures, vol. 18, Article ID 095004, pp. 1-13, 2009.

[15] Q. Du and S. Yang, "Improvement of the EMD method and applications in defect diagnosis of ball bearings," Measurement Science and Technology, vol. 17, no. 8, pp. 2355-2361, 2006.

[16] Z. K. Peng, P. W. Tse, and F. L. Chu, "A comparison study of improved Hilbert-Huang transform and wavelet transform: application to fault diagnosis for rolling bearing," Mechanical Systems and Signal Processing, vol. 19, no. 5, pp. 974-988, 2005.

[17] Q. Gao, C. Duan, H. Fan, and Q. Meng, "Rotating machine fault diagnosis using empirical mode decomposition," Mechanical Systems and Signal Processing, vol. 22, no. 5, pp. 1072-1081, 2008.

[18] X. Zhao, T. H. Patel, and M. J. Zuo, "Multivariate EMD and full spectrum based condition monitoring for rotating machinery," Mechanical Systems and Signal Processing, vol. 27, no. 1, pp. 712728, 2012.

[19] H. Li, L. Yang, and D. Huang, "The study of the intermittency test filtering character of Hilbert-HUAng transform," Mathematics and Computers in Simulation, vol. 70, no. 1, pp. 22-32, 2005.

[20] Z. Wu and N. E. Huang, "Ensemble empirical mode decomposition: a noise assisted data analysis method," Advances in Adaptive Data Analysis, vol. 1, no. 1, pp. 1-41, 2009.

[21] Y. G. Lei, Z. J. He, and Y. Y. Zi, "Application of the EEMD method to rotor fault diagnosis of rotating machinery," Mechanical Systems and Signal Processing, vol. 23, no. 4, pp. 1327-1338, 2009.

[22] Y. G. Lei and M. J. Zuo, "Fault diagnosis of rotating machinery using an improved HHT based on EEMD and sensitive IMFs," Measurement Science and Technology, vol. 20, no. 12, Article ID 125701, 2009. 
[23] J. Zhang, R. Yan, R. X. Gao, and Z. Feng, "Performance enhancement of ensemble empirical mode decomposition," Mechanical Systems and Signal Processing, vol. 24, no. 7, pp. 2104-2123, 2010.

[24] J. S. Cheng, D. J. Yu, J. S. Tang, and Y. Yang, "Application of frequency family separation method based upon EMD and local Hilbert energy spectrum method to gear fault diagnosis," Mechanism and Machine Theory, vol. 43, no. 6, pp. 712-723, 2008. 

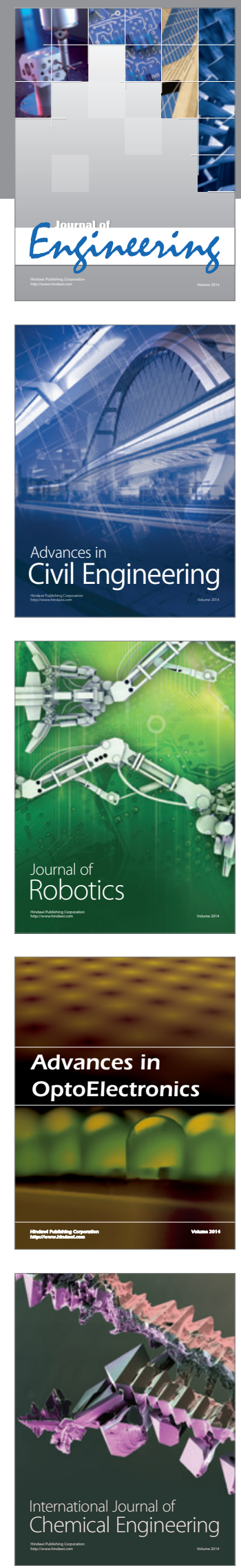

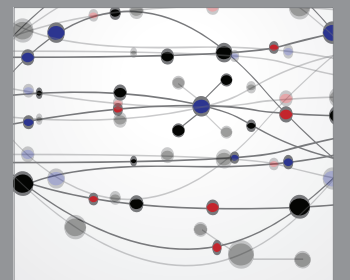

The Scientific World Journal
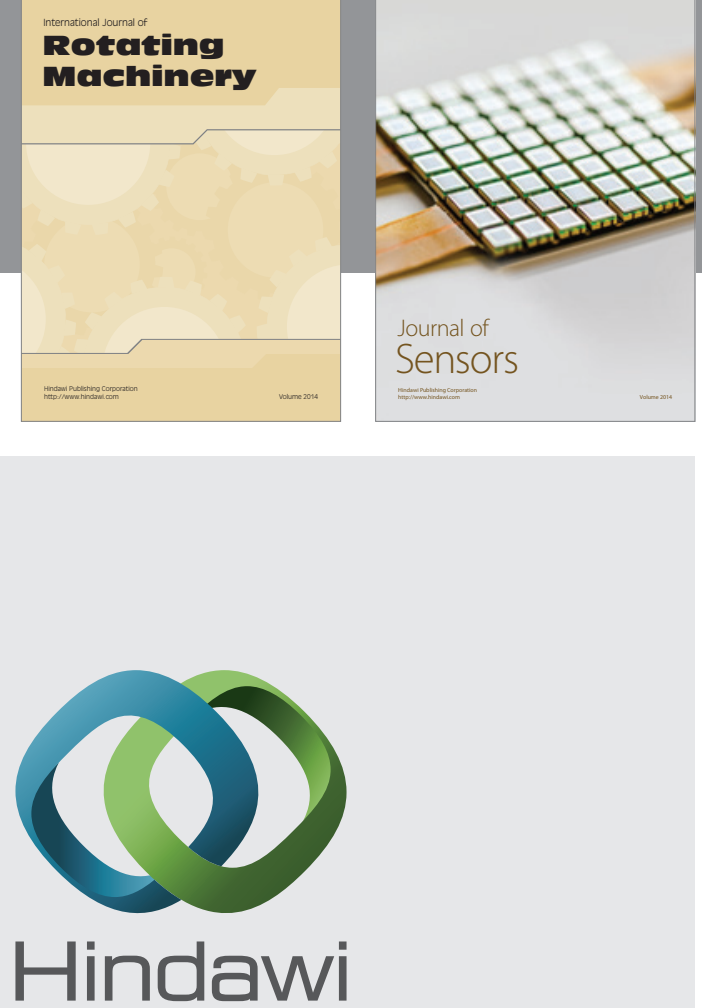

Submit your manuscripts at http://www.hindawi.com
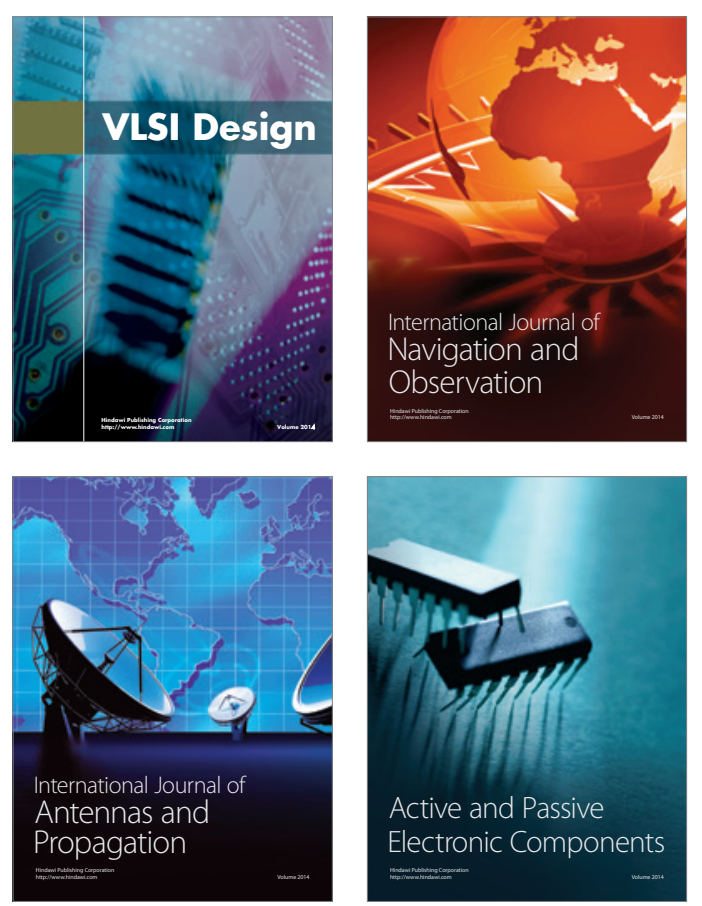
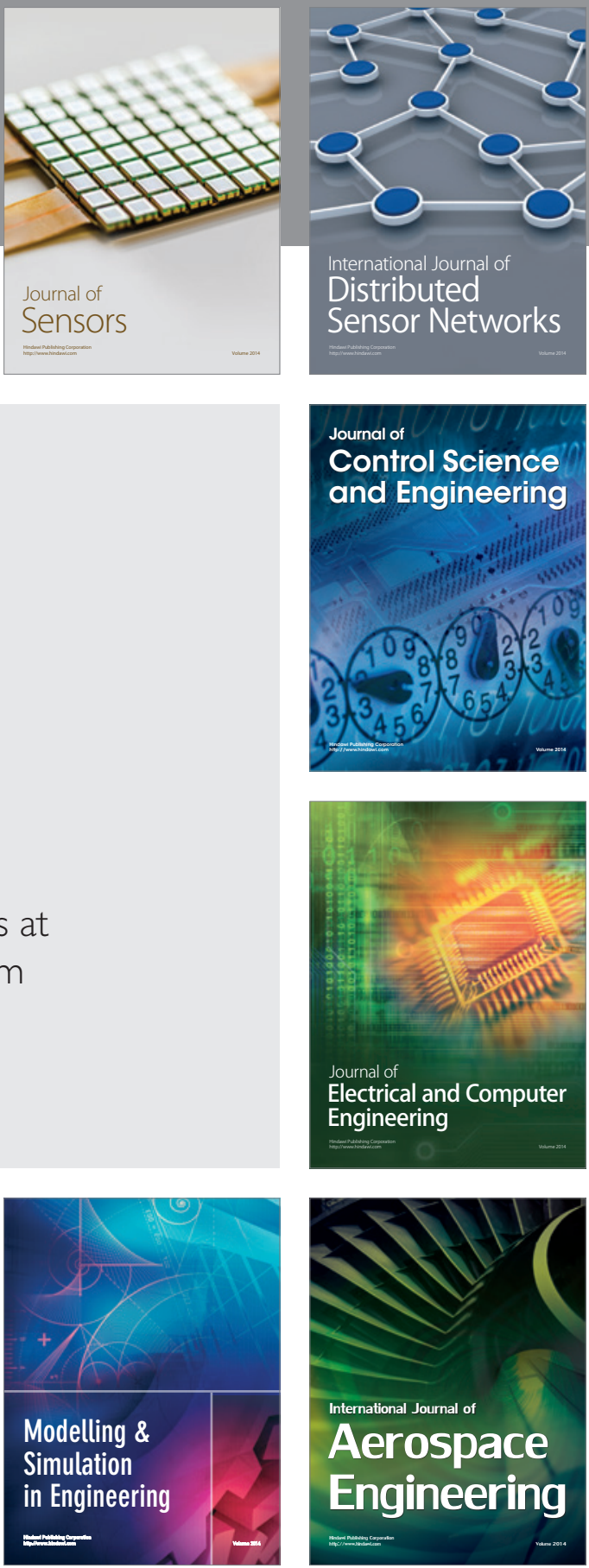

Journal of

Control Science

and Engineering
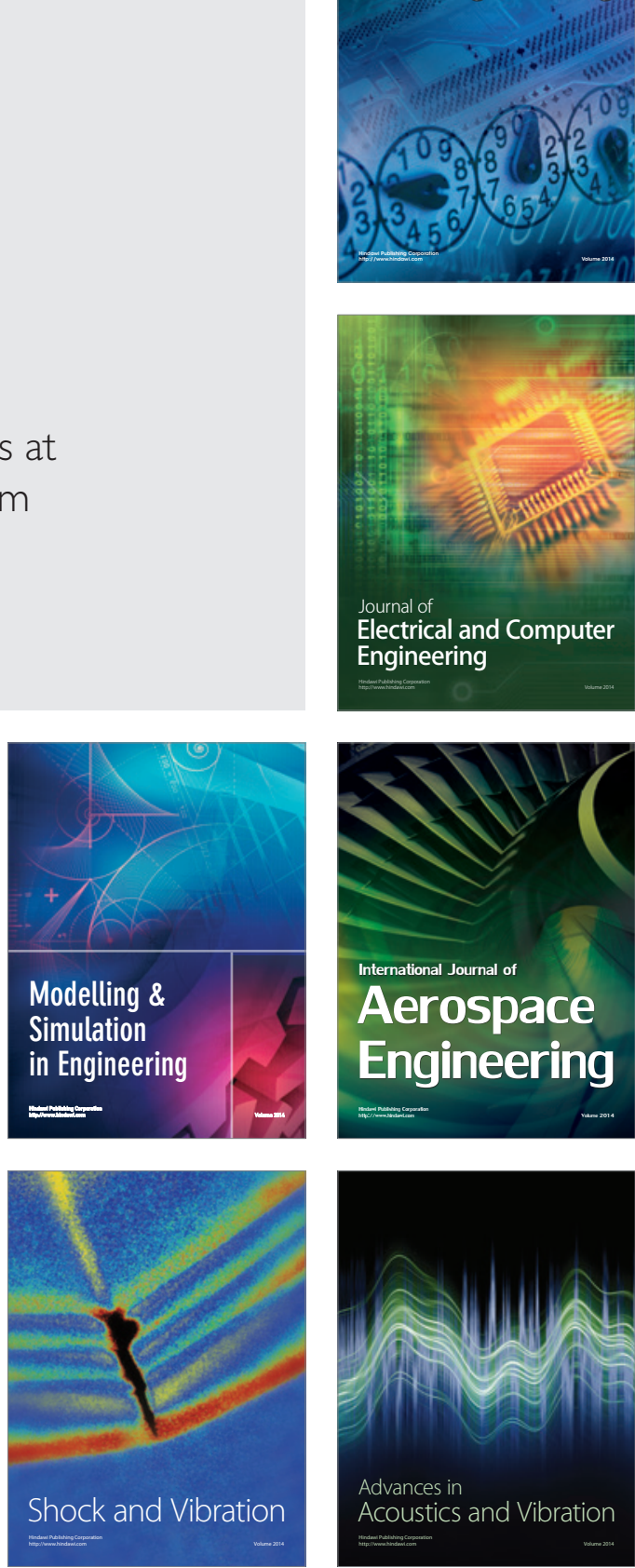